\title{
Ultraviolet Protection by Fabric Engineering
}

\author{
Mukesh Kumar Singh ${ }^{1}$ and Annika Singh ${ }^{2}$ \\ ${ }^{1}$ Uttar Pradesh Textile Technology Institute (Formerly Known as GCTI), Kanpur 208001, India \\ ${ }^{2}$ Institute of Biosciences and Biotechnology, CSJMU, Kanpur, India
}

Correspondence should be addressed to Mukesh Kumar Singh; mukesh70ster@gmail.com

Received 12 November 2012; Revised 15 March 2013; Accepted 16 March 2013

Academic Editor: Anindya Ghosh

Copyright (C) 2013 M. K. Singh and A. Singh. This is an open access article distributed under the Creative Commons Attribution License, which permits unrestricted use, distribution, and reproduction in any medium, provided the original work is properly cited.

Background. The increasing emission of greenhouse gases has evoked the human being to save the ozone layer and minimize the risk of ultraviolet radiation (UVR). Various fabric structures have been explored to achieve desired ultraviolet protection factor (UPF) in various situations. Objective. In this study, the effect of various filament configurations like twisted, flat, intermingled, and textured in multifilament yarns on fabric in different combinations is assessed in order to engineer a fabric of better ultraviolet protection factor (UPF). Methods. In order to engineer a fabric having optimum UV protection with sufficient comfort level in multifilament woven fabrics, four different yarn configurations, intermingled, textured, twisted, and flat, were used to develop twelve different fabric samples. The most UV absorbing and most demanding fibre polyethylene terephthalate (PET) was considered in different filament configuration. Results. The combinations of intermingled warp with flat, intermingled, and textured weft provided excellent UVR protection comparatively at about $22.5 \mathrm{mg} / \mathrm{cm}^{2}$ fabric areal density. The presence of twisted yarn reduced the UV protection due to enhanced openness in fabric structure. Conclusion. The appropriate combination of warp and weft threads of different configuration should be selected judiciously in order to extract maximum UV protection and wear comfort attributes in multifilament woven PET fabrics.

\section{Introduction}

Prolong and frequent exposure of human being against sun causes different dermatological problems [1]. The short-term exposure to ultraviolet radiation (UVR) causes sunburn and in medical science it is erythema $[2,3]$. Prolong sunburn leads to photoageing of skin and results in terms of both nonmelanoma and melanoma skin cancer [4]. The specific band of UV radiation $(100-400 \mathrm{~nm})$ can be classified into three groups on the basis of wavelength. The UVA region of light belongs to span of wavelength $315-400 \mathrm{~nm}$ while the $\mathrm{UVB}$ radiation comes in the range of $280-315 \mathrm{~nm}$ [5]. The region $100-280 \mathrm{~nm}$ is extremely dangerous and belongs to UVC radiation. Divinely, nature has stratospheric ozone layer in atmosphere to absorb UVB and UVC and to block it to reach on earth surface [6]. The intensity of UVR is the highest in Australia and some part of eastern and southern Europe, so protection of adolescents and children (skin thickness is very less) than adults and outdoor workers is very essential [7].
When UVR strikes on textile surfaces, part of it can be transmitted, absorbed, and reflected by the textiles as shown in Figure 1. Different textile fibres have the tendency to absorb a part of UVR and convert it into a different energy form. Another part of radiation is reflected or scattered by the fibr itself and this may be a part of transmitted radiation, because another part of UVR transmits directly through the fabric via interstices between fibres and yarns in the fabrics $[8,9]$. Growing evidence of unusual depletion of stratospheric ozone has encouraged the different research group globally to take new research programme to focus on different aspects of UVR. The Australian radiation laboratory (ARL) is credited to track back the research of UVR protection in 1980s [10]. It is evident that the clothing provides UV protection up to some extent. Clothing is associated with several factors which governs the effectiveness of UVR protection. In addition to the fibrousmaterial, the fabric properties like fabric sett, fibre blend composition, tightness of weave, thickness, and areal density also affects the UPF of resultant fabrics [1115]. Wet processing of textiles (bleaching, usage of UV 


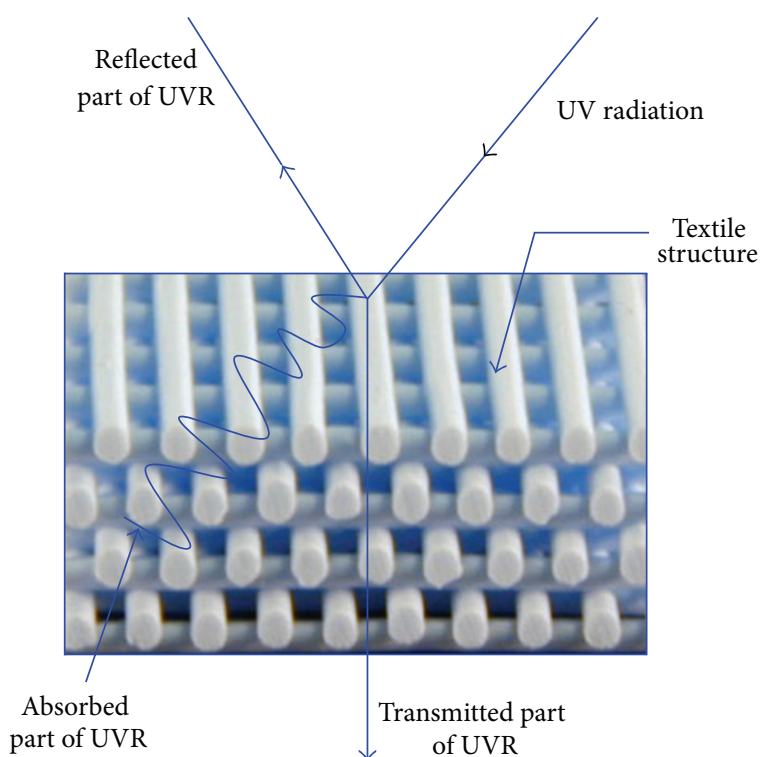

FIGURE 1: UV radiation and textile structure.

TABLE 1: UPF rating and protection grades.

\begin{tabular}{lccc}
\hline Protection grade & Rating & UPF range & Transmission (\%) \\
\hline Good & No value & $20-29$ & $5.0-3.4$ \\
Very good & 30 & $30-40$ & $3.3-2.5$ \\
Excellent & 40 & $>40$ & $<2.5$ \\
\hline
\end{tabular}

absorber, and coloration) also influences the UVR protection function of textiles and some refurbishment activities like wetness, stretch, heat, or chemical treatments [16-21]. The combined effect of these parameters (fibre, yarn, fabric, and wet processing treatment) complicates the subject of UVR protection by clothing. The physicochemical type of fibrous material and fabric openness are other driving parameters to decide the UVR protection of clothing. It has been found that fibres containing conjugated aromatic system like PET are more effective for UVR absorption [9, 14, 22]. The cellulosic fibres having no double bond in their molecular backbone have low UVR absorption capacity, exhibiting comparatively low UPF of textiles made thereof. Natural colour pigment and waxes in natural fibres act as UV absorber. Naturally coloured cotton has higher UV absorption capacity. Different group of scientists conducted that UVR transmission occur through textile through interstices between fibre and yarns and this has been supported by a reduced free space between yarns in the fabric after subsequent washing and consequent increase in ultraviolet protection factor (UPF). In spite of the established fact that yarn structure can influence the UPF of fabric by altering the openness of fabric. Most of the research work was concerned about the influence of yarn linear density but there is no systematic research associated with the UV transmission behaviour of fabric composed of multifilament yarns of different filament configurations [23, 24]. Various UPF ratings and grades are compiled in Table 1.

In this research the efforts were focused to evaluate the effect of filament configuration on UV protection of plain woven fabric for suiting applications. In order to avoid the influence of bleaching dyeing and subsequent finishing treatments, the present research was performed in scoured and desized state of fabrics.

\section{Purpose of Study}

Various yarn configurations are used to produce woven fabrics which influence the yarn and fabric compactness in different ways. Hence, to understand the role of various filament configurations like intermingled, textured, flat, and twisted a systematic and scientific study is concluded in this paper. Findings of this work will definitely helpful to produce PET multifilament yarns based woven fabric of higher UV protection.

\section{Quantitative Assessment of Fabrics for Ultraviolet Protection Factor (UPF)}

Spectrophotometer was used to assess the percent transmission at wavelength intervals upto $5 \mathrm{~nm}$ in the $290-400 \mathrm{~nm}$ spectral span. The UPF is calculated by the following equation [25]:

$$
\mathrm{UPF}=\frac{\sum_{\lambda=290}^{\lambda=400} e(\lambda) \cdot s(\lambda) \cdot \Delta(\lambda)}{\sum_{\lambda=290}^{\lambda=400} e(\lambda) \cdot s(\lambda) \cdot \tau(\lambda) \cdot \Delta \lambda},
$$

where $E(\lambda)$ is the spectral weighting function of erythemal action spectra, $S(\lambda)$ spectral irradiation for appropriate solar radiation spectrum $\left(W \mathrm{~m}^{-2} \mathrm{~nm}^{-1}\right), \tau(\lambda)$ spectral transmittance through specimen, and $\Delta(\lambda)$ appropriate wavelength measuring interval ( $\mathrm{nm})$.

\section{Materials and Methods}

Intermingled, textured, and flat yarns (220/78/00) and twisted yarn (220/78/680) were used to produce 12 different fabric samples. Various combinations of warp and weft considered for this study are shown in Table 2 along with fabric code. The textured yarn was not used as warp because it is not practically feasible to use this yarn as warp. The intermingled yarn was characterized in terms of nip frequency. The nips were counted by placing a free length of yarn on stagnant water surface. The filaments were spread out and then nips become visible. Finally nips were counted and expressed in nips per meter. The typical diagrammatic conformations of four different filament configurations are shown in Figures 2(a) to 2 (d).

All warp beams were produced by direct warping method on Tsudakoma TW/N warping machine. Total numbers of ends were kept 1200. Parallel creel was used with ceramic tensioner by keeping the tension 14 to 18 grams. Flat warps were sized on Tsudakoma KS200 sizing machine with 5\% poly vinyl alcohol (PVA) and $0.25 \%$ antistatic to reduce the static charge generating tendency of PET filament. Twelve fabric samples were manufactured using various combinations of warp and weft of flat, twisted, intermingled, and textured configuration on Nissan NW-155 Water Jet looms under identical operational conditions to keep fabric areal 
TABLE 2: Fabric manufacturing details.

\begin{tabular}{|c|c|c|c|c|c|c|}
\hline $\begin{array}{l}\text { Fabric detail } \\
\text { (warp/weft) }\end{array}$ & $\begin{array}{l}\text { Sample } \\
\text { code }\end{array}$ & Warp versus weft combinations & $\begin{array}{c}\text { Ends } \\
\text { per cm } \\
(\mathrm{EPC})\end{array}$ & $\begin{array}{l}\text { Picks } \\
\text { per cm } \\
(\mathrm{PPC})\end{array}$ & $\begin{array}{l}\text { Fabric areal density } \\
\qquad\left(\mathrm{mg} / \mathrm{cm}^{2}\right)\end{array}$ & $\begin{array}{l}\text { Fabric thickness } \\
\qquad(\mathrm{mm})\end{array}$ \\
\hline FI/I & S1 & Intermingled versus intermingled & 32 & 26 & 22.21 & 0.61 \\
\hline $\mathrm{FI} / \mathrm{Tx}$ & S2 & Intermingled versus textured & 32 & 26 & 22.61 & 0.67 \\
\hline $\mathrm{FI} / \mathrm{F}$ & S3 & Intermingled versus flat & 32 & 26 & 22.11 & 0.62 \\
\hline $\mathrm{FI} / \mathrm{Tw}$ & S4 & Intermingled versus twisted & 32 & 26 & 22.58 & 0.58 \\
\hline $\mathrm{FTw} / \mathrm{I}$ & S5 & Twisted versus intermingled & 32 & 26 & 22.18 & 0.57 \\
\hline $\mathrm{FTw} / \mathrm{Tx}$ & S6 & Twisted versus textured & 32 & 26 & 22.38 & 0.64 \\
\hline $\mathrm{FTw} / \mathrm{F}$ & S7 & Twisted versus flat & 32 & 26 & 22.06 & 0.58 \\
\hline $\mathrm{FTw} / \mathrm{Tw}$ & S8 & Twisted versus twisted & 32 & 26 & 22.95 & 0.60 \\
\hline $\mathrm{FF} / \mathrm{I}$ & S9 & Flat versus intermingled & 32 & 26 & 22.02 & 0.59 \\
\hline $\mathrm{FF} / \mathrm{Tx}$ & S10 & Flat versus textured & 32 & 26 & 22.14 & 0.62 \\
\hline $\mathrm{FF} / \mathrm{F}$ & S11 & Flat versus flat & 32 & 26 & 22.15 & 0.56 \\
\hline $\mathrm{FF} / \mathrm{Tw}$ & S12 & Flat versus twisted & 32 & 26 & 22.17 & 0.58 \\
\hline
\end{tabular}

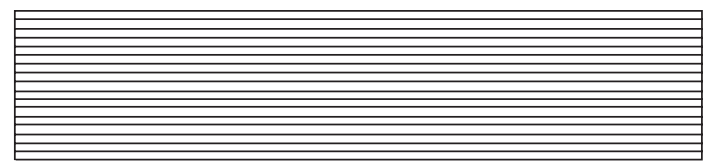

Flat yarn configuration

(a)

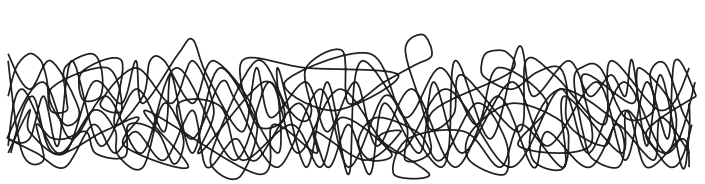

Textured yarn configuration

(c)

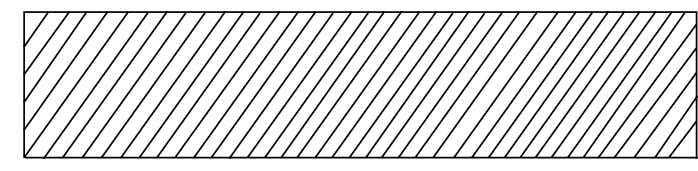

Twisted yarn configuration

(b)

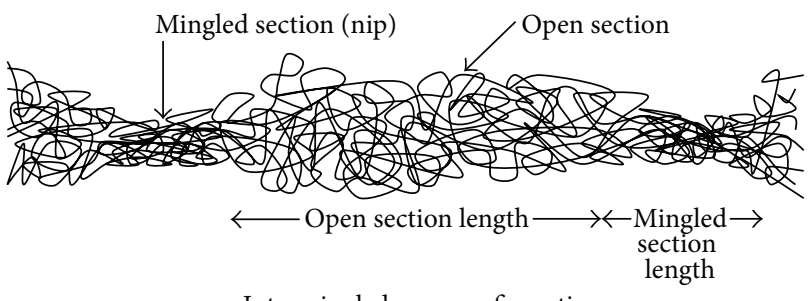

Intermingled yarn configuration

(d)

FIgURE 2: Constituent filament conformations in (a) flat, (b) twisted, (c) textured, and (d) intermingled yarns.

density $22 \mathrm{mg} / \mathrm{cm}^{2}$. The details of fabric constructions are given in Table 2.

The woven fabrics were scoured and desized in Star Hisaka Jet Dyeing Machine by keeping temperature $90^{\circ} \mathrm{C}$ for 60 minutes and used 2 gpl LISAPOL $\mathrm{N}$ nonionic detergent and 2 gpl Finocon-FBOL as desizing agent. After scouring and desizing, fabric samples were passed through Tex Print Stenter at 40 meters per minute speed by keeping the temperature $180^{\circ} \mathrm{C}$. The fabric areal density was maintained at about 120 gram per square meter.

For tensile testing, multifilament yarns were mounted on Instron tensile testing machine (Instron 4200) as per ASTM D-3822-01 with special jaw to prevent any slippage during loading by taking specimen length $500 \mathrm{~mm}$. The jaw speed was adjusted to ensure the yarn breaking time $20 \pm 2 \mathrm{sec}$ as per ASTM D-3822-01. The tenacity at maximum, percent strain, and Young's modulus were obtained based on 64 readings. Air permeability was measured by the TEXTEST FX 3300 air permeability tester. The testing was carried out using test area $5.08 \mathrm{~cm}^{2}$ and test pressure $100 \mathrm{pa}$. An average of 30 observations is reported here. UVF of various fabric samples is measured by using EN 13758-1: 2002.

\section{Results}

Tensile attributes of four different yarns of different configurations are shown in Table 3. The tensile and boiling water response of all four yarns having intermingled, textured, flat, and twisted configurations are shown in Table 3. The tensile and boiling behaviour of yarns having different configuration clearly indicates the effects of filament configuration. The difference in strength and strain \% is not considerable. The filament configuration mainly affects the initial modulus of the yarns as clearly shown in Table 3.

Open porosity is an established governing factor to influence the fabric transmission behaviour, such as heat flow, air, and moisture permeability. The fabric porosity depends on fabric construction, thickness, and surface profile. All twelve 
TABLE 3: Tensile behaviour of different configured yarns.

\begin{tabular}{lcccc}
\hline Yarn sample & Max. tensile strength (cN/Tex) & Strain (\%) & Initial modulus (cN/Tex) & Boiling water shrinkage (\%) \\
\hline Intermingled & 25.53 & 16.24 & 486.6 & 7.1 \\
Textured yarn & 26.12 & 17.97 & 688.8 & 3.8 \\
Flat & 26.92 & 15.05 & 660.7 & 7.5 \\
Twisted & 27.24 & 14.32 & 591.6 & 1.8 \\
\hline
\end{tabular}

fabric samples were woven under identical conditions as mentioned in the second table. The differences in basic manufacturing characteristics originated from four basic configurations of yarn flat, twisted, intermingled and textured. The change in filament configuration in multifilament yarn results in varying porosity as well as thickness. The thickness of fabric samples woven with textured weft was slightly increased and this may be attributed to the highly bulky configuration of textured yarns. The filament configuration influences the openness of fabric structure which is evident from air permeability data (Table 4). The fabric openness based on the total volume of interconnected voids both inside and between the yarns. The four filament yarn configurations were used in this study varying in their openness index drastically. So, it is difficult to measure the actual yarn density because of the fact that yarn is never uniform in terms of its diameter although the packing index of various multifilament yarns varies with change in yarn configurations. At higher twist level yarn surface becomes more irregular and prevents a close packing between the yarns namely higher porosity. The mechanism of intermingled yarn formation consisted mainly of loops and nodes while textured yarn consisted of wavy structure of constituent filaments. The structural features of intermingled, textured, and twisted yarns decided the compactness of the woven structure. The differences in the yarn surface characteristic are clearly identified in pictorial model Figure 2 and the results suggested that these differences influenced the transmission behaviour of woven fabrics.

In order to perceive the effect of multifilament yarn configuration on porosity, the air permeability of the woven structures was measured since it is considered that majority air flow takes place between yarn interstices. As per the results regarding air permeability (Table 4) of woven fabrics of nearly same areal density produced from high twist yarn (S8) was the most permeable. The flat yarn without any twist enabled the least permeability in fabric sample S11 while the fabric sample designated as S6 enabled highest air permeability.

Evidently, the compactness of the flat yarn structure reduces the interyarn stices wherever they found. In consequence of that the fabric sample S11 (FF/F) consists of both flat warp and weft exhibited lowest air permeability amongst different fabric samples. It looks here that at least two elements are opposed to each other: fabric geometry and filament configuration in multifilament yarns or in otherworld size of pores and number of pores per unit area, as similarly concluded by Stankovic et al., 2009, in case of knitted fabrics [26]. Gooding et al., (1964) [27] also similarly inferred that the increased number of pores per unit area would reduce the air permeability due to higher air drag force to air flow due to increase available specific area inside the total number of pores of reduced size. The uneven surface of intermingled, textured, and flat yarn configurations may also have been a reason for closing the interyarn stices in woven fabric and diminishing the air permeability.

The results obtained by UV protection analysis given in Table 4. It is a general consideration that the majority of interyarn stices and the macroporosity of yarns and fabrics are the major factors influencing the UV transmission through fabrics. There is an old concept that UV transmission is not possible through yarns $[8,10,11]$, but recent research inferred that UV transmission is possible through yarns. The UV protection analysis of different fabrics produced from yarns having different configurations suggested that the yarn structure playing a decisive role to decide the UV protection by fabrics. The fabric sample S11 consists of flat warp and flat weft exhibited the lowest air permeability due to the lowest openness and permitted the lowest amount of UVA and UVB radiation to be passed through. The fabric sample S8 consists of twisted warp and weft thread recognized by highest air permeability that translated in terms of highest UVA and UVB transmittance. The fabric sample S1 consists of both warp and weft yarn intermingled configuration (FI/I) exhibited higher UVA and UVB protection than S2 (FI/Tx), that is, fabric made with intermingled warp and textured weft. This may be attributed to the fact that textured configuration has comparatively higher open structure than intermingled configuration in which nodes remain present at regular interval. The UVA and UVB transmittance reduced when weft was flat with intermingled warp in S3 (FI/Tw). This may be attributed again to yarn configuration, that is, flat yarns are most compact among the four considered configurations (intermingled, textured, flat, and twisted). The UV protection again reduced as twisted yarn used as weft. This may be attributed to the fact that twisted yarns leave higher interyarn space than flat yarn [26]. The twisted warp was used with different weft thread of varying configurations from S5 to S8; the UV protection followed the trend $\mathrm{S} 7>\mathrm{S} 5>\mathrm{S} 6>\mathrm{S} 8$.

The above results and trend showed that yarn configuration is an important variable to play with UV protection of multifilament woven PET fabrics. The flat yarn with zero twist offered most compact structure which was again configured with least air permeability in S11 fabric samples. This may be attributed to the fact that each filament in zero twist flat yarn is free to tie in free space wherever they get and in consequence of that maximum compactness constituted. The intermingled yarn configuration reached at second position to achieve compactness in fabric structure followed by textured configuration of multifilament PET yarns. This may be explained on the basis of ideal geometry of textured configuration (Figure 2). The textured configuration consists 
TABLE 4: Porosity, transmission, and ultraviolet protection factor (UPF) values.

\begin{tabular}{|c|c|c|c|c|c|c|}
\hline \multirow{2}{*}{ Sample code } & \multirow{2}{*}{ Air permeability $\left(\mathrm{cm}^{3} / \mathrm{cm}^{2} / \mathrm{s}\right)$} & \multirow{2}{*}{ Moisture vapour transmittance (\%) } & \multicolumn{3}{|c|}{ Transmission (\%) } & \multirow[t]{2}{*}{ UPF } \\
\hline & & & UVA & UVB & UVC & \\
\hline S1 & 5.128 & 67.45 & 0.83 & 0.86 & 0.89 & $40+$ \\
\hline S2 & 12.92 & 71.92 & 0.92 & 0.95 & 0.99 & $40+$ \\
\hline S3 & 3.02 & 64.94 & 0.78 & 0.80 & 0.80 & $40+$ \\
\hline S4 & 8.35 & 69.21 & 0.87 & 0.90 & 0.94 & $40+$ \\
\hline S5 & 75.45 & 68.24 & 1.12 & 1.17 & 1.20 & 39.8 \\
\hline S6 & 151.04 & 71.04 & 1.85 & 1.99 & 2.00 & 33.6 \\
\hline S7 & 64.17 & 66.16 & 1.01 & 1.08 & 1.10 & $40+$ \\
\hline S8 & 129.44 & 70.16 & 1.65 & 1.73 & 1.78 & 37.4 \\
\hline S9 & 2.32 & 64.53 & 0.75 & 0.71 & 0.69 & $40+$ \\
\hline S10 & 33.41 & 69.28 & 0.99 & 1.00 & 1.00 & $40+$ \\
\hline S11 & 1.46 & 57.72 & 0.682 & 0.693 & 0.685 & $40+$ \\
\hline S12 & 12.11 & 68.63 & 0.956 & 0.998 & 1.006 & $40+$ \\
\hline
\end{tabular}

TABLE 5: Bending and compression behavior of fabric samples.

\begin{tabular}{lccc}
\hline Fabric code & B & LC & WC \\
\hline S1 & 0.045 & 0.693 & 0.037 \\
S2 & 0.039 & 0.845 & 0.027 \\
S3 & 0.244 & 0.749 & 0.038 \\
S4 & 0.051 & 0.774 & 0.029 \\
S5 & 0.048 & 0.933 & 0.021 \\
S6 & 0.055 & 0.929 & 0.025 \\
S7 & 0.212 & 0.911 & 0.022 \\
S8 & 0.072 & 0.881 & 0.021 \\
S9 & 0.079 & 0.929 & 0.032 \\
S10 & 0.043 & 0.042 & 0.025 \\
S11 & 0.383 & 0.843 & 0.054 \\
S12 & 0.047 & 0.845 & 0.026 \\
\hline
\end{tabular}

of wavy filament structure, offers higher UV transmission through yarn itself. The twisted yarn is very compact in its structure and leaves maximum porosity as evident by air permeability data in case of fabric sample S8 consists of both twisted warp and weft.

The moisture vapour permeability $\%$ is vary important attribute of wearing comfort follow a typical trend and that is, $\mathrm{Tw}>\mathrm{Tx}>\mathrm{I}>\mathrm{F}$ (i.e moisture vapour permeability is highest for twisted configurations and lowest for flat configurations. These results indicated that interfibre space and interyarn stices both contribute to decide the moisture vapour transmissibility of fabric samples.

The bending and compression behaviour of fabric samples exhibited that yarn configuration and appropriate combination of warp and weft threads of different structure are decisive factor to engineer it for better fabric hand and compiled in Table 5. The twisted yarn configuration exhibited highest bending rigidity. The bending rigidity of $\mathrm{S} 3$ having intermingled warp and flat weft showed higher bending rigidity. Fabric samples S7 (consist of twisted warp and flat weft) and S11 (consist flat warp and flat weft) also showed higher bending toughness as shown in Table 5 .
The compression behaviour of fabric is among the prime contributors to decide the sensorial comfort of the fabric samples (Kawabata et al., 1983) [28]. The linearity in compression (LC), compression energy (WC), and resiliency of compression (RC) data (Table 5) for different fabric samples reflect the influence of yarn configuration on compression behaviour of fabric samples. The compression energy of fabric sample S2 is lowest which indicates the lowest resistance against fabric compression while the S11 (F F/F) consists of both flat warp and flat weft threads exhibited highest compression energy, namely indication of difficult to compress.

\section{Conclusion}

In conclusion, yarn configuration proved to be the remarkable determinant of the UV protection characteristics of woven fabrics through the effectiveness of filament configuration, that is, fibre packing in the multifilament yarn. The appropriate combination of warp and weft threads of different configuration should be selected in order to produce the maximum UV protection and other wear comfort properties of multifilament woven PET fabrics. The mentioned research provides guidelines for engineering multifilament woven PET fabrics to achieve adequate UPF on the basis of yarn configuration of warp and weft threads. In order to achieve ideal UV protective clothing, fabric engineering may prove its crucial role.

\section{Abbreviations}

SPF: Sun protection factor

UVR: Ultraviolet radiation reaching the earth's surface, ultraviolet radiation (UVR).

\section{References}

[1] D. Saravanan, "UV protection textile materials," Autex Research Journal, vol. 7, no. 1, pp. 53-62, 2007.

[2] S. Dornelles, J. Goldim, and T. Cestari, "Determination of the minimal erythema dose and colorimetric measurements as 
indicators of skin sensitivity to UV-B radiation," Photochemistry and Photobiology, vol. 79, no. 6, pp. 540-544, 2004.

[3] M. K. Singh, "Sun protective clothing," Asian Textile Journal, vol. 14, no. 1-2, pp. 91-97, 2005.

[4] I. Algaba, A. Riva, and P. C. Crews, "Influence of fiber type and fabric porosity on the UPF of summer fabrics," AATCC Review, vol. 4, no. 2, pp. 26-31, 2004.

[5] European Standard EN 13758-1, "Textiles-Solar Ultraviolet Protective Properties-Part-I: Methods of test for Apparel Fabrics," 2002.

[6] C. R. Roy, H. P. Gies, and S. Toomey, "The solar UV radiation environment: measurement techniques and results," Journal of Photochemistry and Photobiology B, vol. 31, no. 1-2, pp. 21-27, 1995.

[7] M. Pailthorpe, "Textile and sun protection: the current situation," Australasian Textiles, vol. 14, no. 6, pp. 54-66, 1994.

[8] J. Alvarez and B. Lipp-Symonowicz, "Examination of the absorption properties of various fibres in relation to UV radiation," Autex Research Journal, vol. 3, no. 2, pp. 72-77, 2003.

[9] T. Gambichler, A. Avermaete, A. Bader, P. Altmeyer, and K. Hoffmann, "Ultraviolet protection by summer textiles. Ultraviolet transmission measurements verified by determination of the minimal erythema dose with solar-simulated radiation," British Journal of Dermatology, vol. 144, no. 3, pp. 484-489, 2001.

[10] T. Gambichler, K. L. Hatch, A. Avermaete, P. Altmeyer, and K. Hoffmann, "Influence of wetness on the ultraviolet protection factor (UPF) of textiles: in vitro and in vivo measurements," Photodermatology Photoimmunology and Photomedicine, vol. 18, no. 1, pp. 29-35, 2002.

[11] C. A. Wilson and A. V. Parisi, "Protection from solar erythemal ultraviolet radiation-simulated wear and laboratory testing," Textile Research Journal, vol. 76, no. 3, pp. 216-225, 2006.

[12] M. Khazova, J. B. O’Hagan, and K. L. Grainger, "Assessment of sun protection for children's summer 2005 clothing collection," Radiation Protection Dosimetry, vol. 123, no. 3, pp. 288-294, 2007.

[13] H. P. Gies, C. R. Roy, G. Elliott, and W. Zongli, "Ultraviolet radiation protection factors for clothing," Health Physics, vol. 67, no. 2, pp. 131-139, 1994.

[14] S. Davis, L. Capjack, N. Kerr, and R. Fedosejevs, "Clothing as protection from ultraviolet radiation: which fabric is most effective?" International Journal of Dermatology, vol. 36, no. 5, pp. 374-379, 1997.

[15] I. E. S. Clark, K. J. L. Grainger, J. L. Agnew, and C. M. H. Driscoll, "Clothing protection measurements," Radiation Protection Dosimetry, vol. 91, no. 1-3, pp. 279-281, 2000.

[16] D. G. Stanford, K. E. Georgouras, and M. T. Pailthorpe, "The effect of laundering on the sun protection afforded by a summer weight garment," Journal of the European Academy of Dermatology and Venereology, vol. 5, no. 1, pp. 28-30, 1995.

[17] A. V. Parisi, M. G. Kimlin, L. Mulheran, L. R. Meldrum, and C. Randall, "Field-based measurements of personal erythemal ultraviolet exposure through a common summer garment," Photodermatology Photoimmunology and Photomedicine, vol. 16, no. 3, pp. 134-138, 2000.

[18] K. Hoffmann, K. Kaspar, T. Gambichler, and P. Altmeyer, "In vitro and in vivo determination of the UV protection factor for lightweight cotton and viscose summer fabrics: a preliminary study," Journal of the American Academy of Dermatology, vol. 43, no. 6, pp. 1009-1016, 2000.
[19] S. Q. Wang, A. W. Kopf, J. Marx, A. Bogdan, D. Polsky, and R. S. Bart, "Reduction of ultraviolet transmission through cotton T-shirt fabrics with low ultraviolet protection by various laundering methods and dyeing: clinical implications," Journal of the American Academy of Dermatology, vol. 44, no. 5, pp. 767$774,2001$.

[20] J. H. Xin, W. A. Daoud, and Y. Y. Kong, "A new approach to UVblocking treatment for cotton fabrics," Textile Research Journal, vol. 74, no. 2, pp. 97-100, 2004.

[21] M. Gorensek and F. Sluga, "Modifying the UV blocking of polyester fabric," Textile Research Journal, vol. 74, no. 6, pp. 469474, 2004.

[22] P. C. Crews, S. Kachman, and A. G. Beyer, "Influences on UVR transmission of undyed woven fabrics," Textile Chemist and Colorist, vol. 31, no. 6, pp. 17-26, 1999.

[23] G. Hustvedt and P. C. Crews, "Textile technology: the ultraviolet protection factor of naturally-pigmented cotton," Journal of Cotton Science, vol. 9, no. 1, pp. 47-55, 2005.

[24] A. Riva, I. Algaba, and M. Pepió, "Action of a finishing product in the improvement of the ultraviolet protection provided by modal and modal sun fabrics: modelisation of the effect," Fibers and Polymers, vol. 8, no. 2, pp. 205-211, 2007.

[25] J. M. Menter and K. L. Hatch, "Clothing as solar radiation protection," Current Problems in Dermatology, vol. 31, pp. 50-63, 2003.

[26] S. B. Stankovic, D. Popovic, G. B. Poparic, and M. Bizjak, "Ultraviolet protection factor of gray-state plain cotton knitted fabrics," Textile Research Journal, vol. 79, no. 11, pp. 1034-1042, 2009.

[27] A. C. Goodings, "Air flow through textile fabrics," Textile Research Journal, vol. 34, no. 8, pp. 713-724, 1964.

[28] S. Kawabata, "Recent development in the objective measurement of apparel fabric handle, quality and physical properties," in Objective Evaluation of Apparel Fabrics, R. Postle, S. Kawabata, and M. Niwa, Eds., pp. 15-28, Textile Machinery Society of Japan, Osaka, Japan, 1983. 

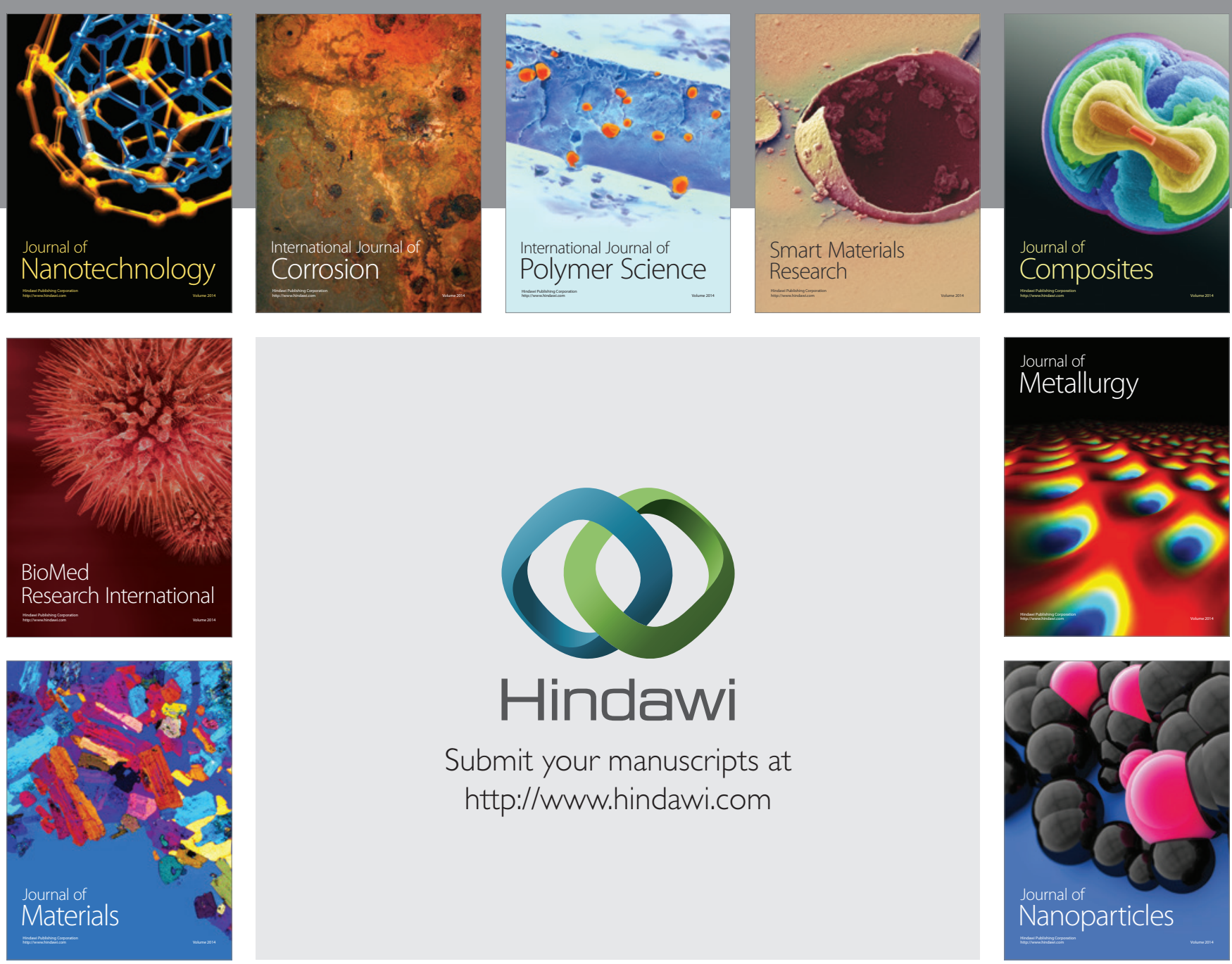

Submit your manuscripts at http://www.hindawi.com
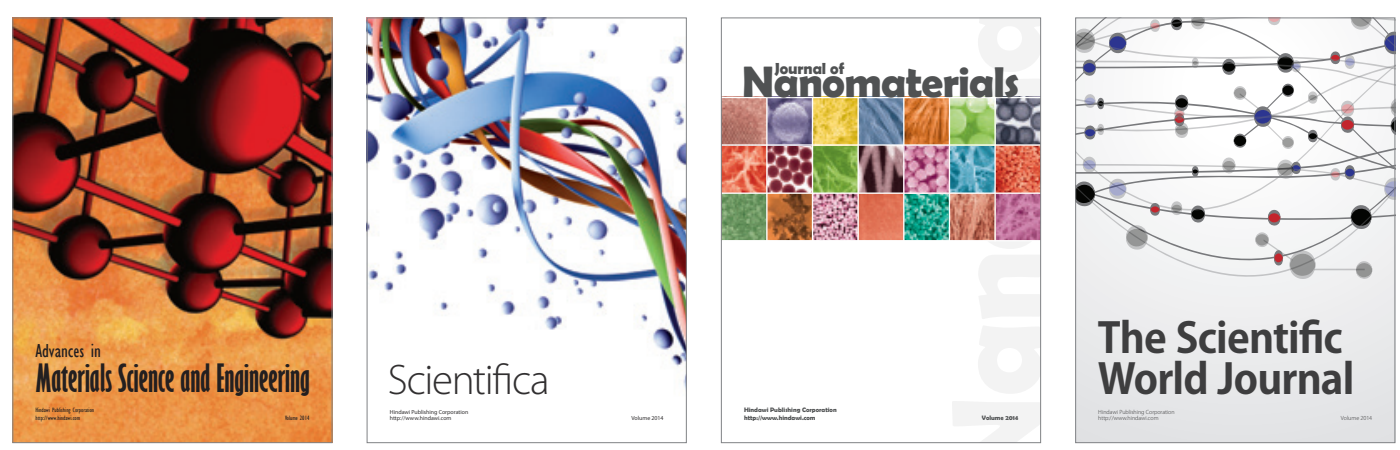

\section{The Scientific World Journal}
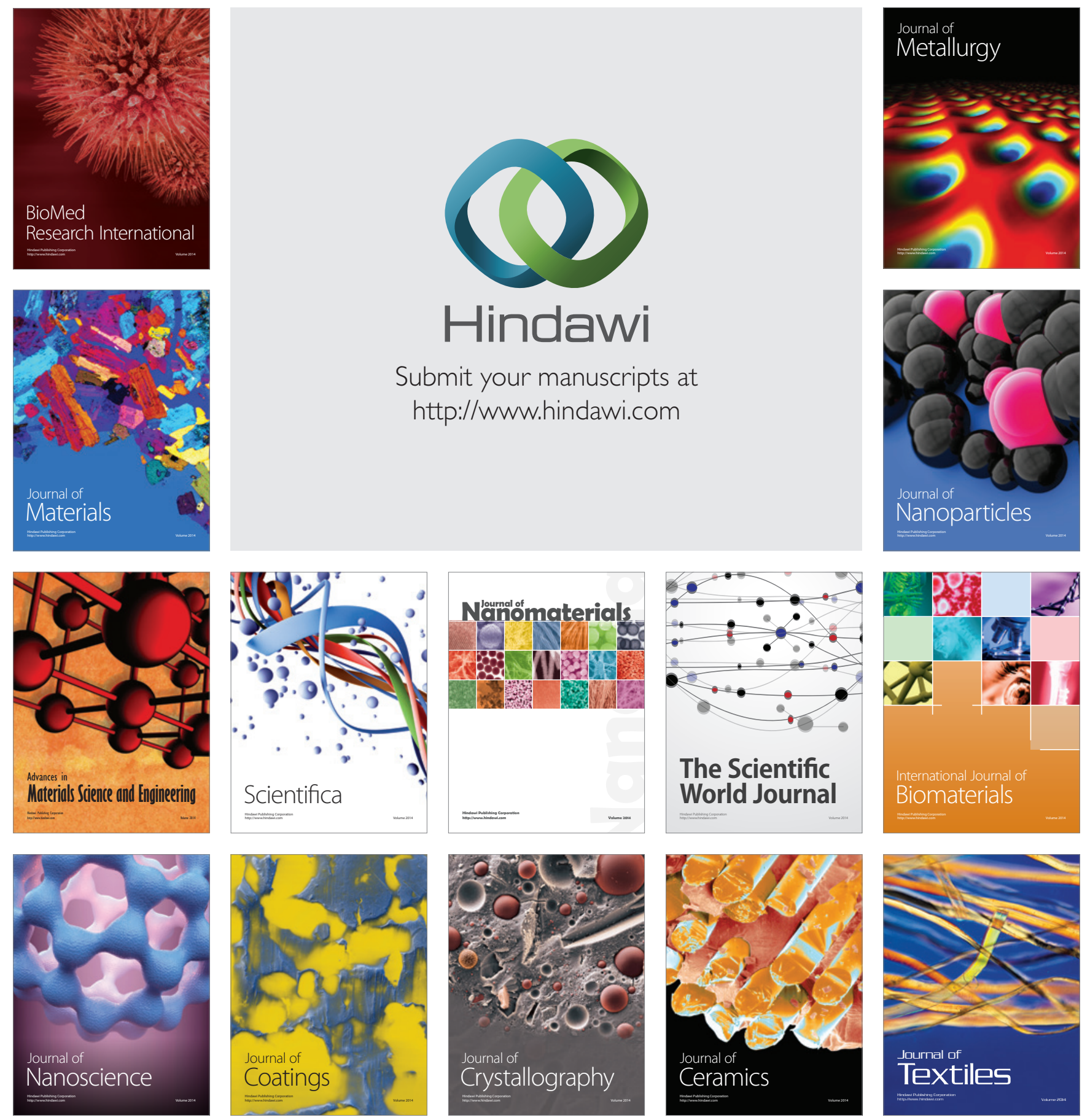